\title{
Influences on the study of vulvar anatomy and disease
}

\author{
Ian S. C. Jones \\ Women’s and Newborn Services, Royal Brisbane and Women’s Hospital, Brisbane and University of Queensland, Herston, Australia \\ Email: ian_jones@health.qld.gov.au
}

Received 24 May 2012; revised 30 June 2012; accepted 12 July 2012

\begin{abstract}
The study of Gynaecology over the years has been influenced by the culture and social attitudes of society to the body as a whole and to the genital organs in particular. Variations in these attitudes between different cultures and at different times have influenced the subsequent rate of progress in the study of the vulva and its diseases.
\end{abstract}

Keywords: Vulvar; Cancer; Attitudes; Communication; Scientific Developments

\section{INTRODUCTION}

Overviews of medical history usually commence with reference to stone figures and cave drawings that date back to between 40,000 and 16,000 BC. However, Australia's Aborigine people who arrived in Australia between 60,000 and possibly 125,000 years ago [1] are known to have used stone tools and red ochre pigment dating back over 60,000 years to depict various aspects of their semi-nomadic hunter gatherer life style and relationships between other persons including religious and ceremonial activities.

The temptation to enter into the debate [2] as to whether rock art is indeed art as it may be considered by western society has been resisted, as has the use of such terms as rock imagery, pictograms, petroglyphs and rock engravings.

\section{AUSTRALIAN ABORIGINAL ART AND DESCRIPTIONS OF FEMALE GENITALIA}

Prior to the arrival of Europeans (European colonisation), Australian Aborigines lived in communities variously referred to as tribes or mobs. They lived in close association with nature and depended absolutely on what their physical environment had to offer. They had a significant and interrelated three-fold relationship between themselves and other group members; between themselves and nature; and between themselves and gods, spirits and supernatural beings [3]. In addition, their traditional health beliefs are interconnected with these relationships [4].

In Australian Aboriginal society food gathering and fertility were of great importance. As regards fertility the basic emphasis was on food and sex. In some situations sex was treated frankly whereas in other situations sex was expressed in song-poems, ritual objects, emblems, rock art and bark paintings [3]. Some of these objects are of medical interest with representations of the human form showing the female breast, menstruating females, sexual activity, (some of which can be considered pornographic [5]), and male and female external genitalia. Female figures usually have small breasts but large anatomically detailed vulvas [6]. The depiction of large external genitalia in the drawings of these "love magic figures" from both sexes was considered by Taylor [6] to suggest the licentious behaviour of the various spirits. In Aboriginal culture there are strong links between the ancestral spirit world and the material world. As Dean [7] also points out "there is no sharp distinction between the sacred and the secular, since the spirit world and human world interpenetrate".

Traditional healers were trained to remove the influence of sorcery and evil spirits and to restore the wellbeing of the soul or spirit [8] and because of these skills were held in high regard [9]. Traditional healers tended to be male dominated, although there were female healers in some communities [10]. Following colonisation the life-style of many Australian Aborigines changed significantly. Much of this change came about as a result of dispossession of their land, social disruption, racism, cultural suppression and discriminatory government practices. As a result of these changes the use of traditional medicine and healing practices also changed according to the impact of these changes on the local groups being considered [11]. At present the consequences of these actions we can only guess as to how this change/absence to the use of traditional medicine and healing practices affected the management of various conditions affecting the female external genitalia.

Care must be taken in making generalised statements about Australian Aborigines because of the great diversity among different communities and societies [11]. 
Also the literature which considers the health beliefs of Australian Aborigines from more recent times must distinguish between those who still live in rural and remote regions and those who live in metropolitan areas [12].

Until the arrival of Europeans Australian Aborigines did not develop writing skills but relied on various art forms e.g. rock and bark drawings, songs, dance, rituals, other performances and story telling to pass on their cultural heritage and knowledge. In Australian Aboriginal culture there is a clear cut division between men's and women's business and this is important when considering gender specific health problems [13]. However this division between the sexes does not seem to be an issue within the realm of Australian Aboriginal art. Information promoting The Indigenous Collection within The Ian Potter Centre of the National Gallery of Victoria claims that Aboriginal art is the oldest continuing tradition of art in the world. Hence the art form and specifically the representations of human anatomy have not changed significantly over time unlike that reported in the English literature which we are about to consider.

\section{DESCRIPTIONS OF THE FEMALE GENITALIA BY OTHER CULTURES}

In the English literature and prior to 1800 the history of Obstetrics and Gynaecology showed that obstetrics, more correctly midwifery, was documented in greater detail than the practise of what we now refer to as gynaecology. In comparison with midwifery the sparse records on gynaecology favoured writings about menstruation, the uterus, ovaries and fallopian tubes with little recorded attention paid to the female external genitalia. The records on the female external genitalia that are available extend back over several thousand years. Although the earliest representations of the human body in the form of cave drawings and stone figures date back to the Middle Aurignacian period (40,000-16,000 BC), it is not until the ancient Egyptians (2000 BC) that specific references to the vulva were recorded in the Kahun Papyrus [12].

In India the ancient documents of the Hindus, known as the Vedas, were written 1500 years before the Christian era [14]. Charaka (a Hindu writer on medical issues, born $300 \mathrm{BC}$ ) described tumours occurring on the vulva and pruritus vulvae in the $30^{\text {th }}$ chapter of his 120 chapters in the "Ayur Veda" [14].

In Western countries social attitudes to the body as a whole and to the genital organs in particular, influenced the subsequent rate of progress in the study of the vulva. For instance, the Greeks in the time of Hippocrates (460$370 \mathrm{BC})$ referred to the external genitalia as "the shameful parts". Although they inspected the external genitalia their initial descriptions of vulvar pathology were only recorded in vague terms such as ulcerations, aphthae and vegetations [14]. As time went by their descriptions became more explicit. During the first century AD, Celsus (27 BC-50 AD, it is unknown if he was a practising physician or where he was born) described the imperforate hymen and Rufus (Ephesian, who resided in Rome 98-117 AD, physician and anatomist) wrote a detailed text of the human body in which he named various structures including parts of the vulva [14]. An extract of this writing follows using terminology not in current practice.

The privates of women, the triangular extremity of the hypogastric region is called the comb, while others speak of it as the episeion. The aperture of the genitals is called the skisma. The nymphe or the murton are the names applied to that pendulous fleshy body in the midline; others call it the hypodermis; while some prefer to call it the clitoris. Titillation of this structure for lascivious purposes is designated as clitorising.

Soranus (An Ephesian physician who worked in Rome during the period 98-138 $\mathrm{AD}$ ) described the vagina and the external genitalia. He wrote of the hymen and the difference between that of the virgin and that of the non-virgin. Galen's (130-199 AD, physician and anatomist) fame in gynaecology was based on his anatomical dissections and descriptions of the female genitalia. Galen mentions the use of a "scalpellus" in incising an imperforate hymen [14].

During the Byzantine period (fourth to seventh century AD) Vindicianus, an African born Latin physician [14] wrote a "Gynaecia" dealing with anatomy, embryology and physiology of the female genitalia. Aetius of Amida (700 AD, Mesopotamian physician) was the first eminent Christian physician and writer of texts. In his writings "Diseases of the External Genitalia" he described a Bartholin's cyst recognising its location and the possibility of it being bilateral. He also described hypertrophic changes of the clitoris and "various ulcerations of the pudenda and labia which may assume a malignant nature and bleed freely, especially after coitus, exercise or following a speculum examination.” [14] (p. 185). Paulus Aegineta (625-690 AD, Greek the last of the Byzantine medical writers and surgeon) wrote on pudendal ulcers, condylomata, haemorrhoids about the female genitalia and hermaphrodites recommending excision of the superfluous parts and treating the raw surfaces like an ordinary wound [14].

Ricci summarises the gynaecological data in the Arabian medical manuscripts (800-1200) as being "scanty and reflective of the views of the Greeks with gynaecology being neglected even more than obstetrics with the practice of both specialties being left to midwives.” [14] (p. 221). He suggested that this occurred because their physicians and the population as a whole had a "profound 
aversion to both gynaecology and obstetrics based on a mistaken sense of values and prudery.”

\section{THE ADVENT OF ANATOMICAL DISSECTION}

Further progress in understanding anatomy was delayed until the sixteenth century when anatomical dissection of the human body was permitted and the findings obtained were recorded with accurate drawings. However, at this stage in time there was still considerable confusion on the function of the Fallopian tubes and the number of compartments in the uterine cavity. This confusion had arisen as a result of the extrapolation of findings from animal dissections to the human. Even the records of Vesalius (1514-1564, anatomist and military surgeon) demonstrated the influence of Galen's teachings as shown in his drawing of the uterine cavity which indicated a fundal septum protruding into it. Apart from this possible error (questioned because a uterus subseptus of minor degree can have this appearance), he accurately described each organ within the whole genital tract with the anatomical illustrations attributed to John de Calcar and published in 1543 as his "De Corporis Humani Fabrica". Fallopio (1523-1562, professor of anatomy, surgery and botany at Padua) of fallopian tube fame was the first to mention the clitoris as a muscular structure and redescribed the hymen as a definite structure [14]. Fabricius (1537-1619, anatomist), wrote in his textbook of surgery "Opera Chirurgica” brief chapters on the imperforate hymen and adherent labia in addition to other gynaecological problems.

In the seventeenth century a more detailed assessment of anatomical structures became possible with the development of preserving anatomical specimens and injecting blood vessels [14]. Seventeenth century texts solely devoted to gynaecology are few. In 1618 the posthumous "Opuscula Medica” of Ronsseus (1525-1596, Flemish physician) was published and contained a section on diseases of women. De Graaf (1641-1673, Dutch anatomist) accurately described not only the ovary and its follicles, but the entire genital tract. His text on the female genital tract contains chapters on the pudendum, the clitoris, clitoral crura and its blood supply, the mons, the hymen, the urinary meatus [14].

At about this time Leeuwenhoek (1632-1723, Dutch microscopist) and Hooke (1635-1703, English microscopist and curator of the Royal Society of London) developed the prototype of the microscope. Further development of this instrument was to advance the study of vulvar pathology considerably but that was still two hundred years in the future. In 1693, Vater-Schondorff recorded a case of carcinoma of the labia majora in his Wittenberg thesis, and the lymphatic drainage of the genitalia was correctly detailed in Anton Nuck's (16501692, Dutch anatomist) textbook of anatomy which was published in 1722. The way was now clear for further meaningful studies of vulvar malignancy.

Gynaecology and gynaecological surgery as a distinct specialty did not occur in the eighteenth century. However, by the eighteenth century obstetrics was well on the way to becoming a definite speciality [14]. Smellie (1697-1763, Scottish obstetrician who practiced in London) gave a description of the vulva in his chapter entitled "Of the external and internal Parts of Generation proper to women” [14] and provided a detailed illustration in Plate IV [15] published in 1783.

The concept of pre malignant lesions developed nearly 150 years later when Schwimmer (1877, German) reported white lesions in the mouth and tongue describing them as leukoplakia. It was then recognised that similar lesions could occur at other sites on the body. In 1885 kraurosis vulvae was described by Breisky (1832-1889, Czech gynaecologist) and two years later in 1887 Hallopeau (1842-1919, French dermatologist) described what is now known as lichen sclerosus. These were conditions considered to be premalignant lesions of the vulva.

The use of histology for the study of vulvar conditions gained momentum. Webster (1863-1950, Canadian gynaecologist) in 1891 and Sanger (German gynaecologist) in 1894 studied vulvar tissue excised from patients with intractable pruritus vulvae. They reported upon an inflammatory affection of the corium and noted excision cured the symptoms. Since that time many authors have added to the literature on vulvar disease, its causes and treatments. However this more recent history is beyond the current study's time period.

Distance and modes of transport have played an important part in how once isolated communities were able to literally expand their horizons and share knowledge. Initially Europe, England, Egypt, Middle East and India were isolated from each other but adventurers broke down the barrier of distance and expanded their knowledge. However the Australian Aborigines remained isolated because of distance and the lack of long distance transport which in turn slowed their progress in the study of medicine and its diseases as we now know it. However isolation did bring the benefit of isolating them from western diseases until they were introduced by the colonists.

\section{CONCLUSION}

History shows how culture, religion and social attitudes (together with natural and man made disasters and the laws of the times), influenced the subsequent rate of progress in the study of medicine and its diseases. This is nowhere more apparent than with the study of the vulva 
and its diseases.

\section{ACKNOWLEDGEMENTS}

I acknowledge the work of Professor James Ricci from the Department of Gynaecology and Obstetrics at the City Hospital New York and his Genealogy of Gynaecology.

I thank Professor John Pearn, Professor of Paediatric and Child Health, The University of Queensland for his encouragement and advice in the preparation of this paper.

\section{REFERENCES}

[1] Roberts, R.G., et al. (1994) The human colonisation of Australia: Optical dates of 53,000 and 60,000 years bracket human arrival at Deaf Adder Gorge, Northern Territory. Quaternary Science Review, 13, 575-583. doi:10.1016/0277-3791(94)90080-9

[2] Whitley, D.S. (2001) Handbook of rock art research. AltraMira Press, California.

[3] Berndt, R.M. (1974) Australian aboriginal religion.

[4] Tynan, B.J. (1999) Medical systems in conflict: A study of power. Government Printer, Brisbane.

[5] Roth, W.E. (1897) Ethno-pornographic Figures in ethnological studies among the north-west-central Queensland Aborigines. Edmund Gregory. Government Printer, Brisbane.

[6] Tacon, P.S.C and Davies, S.M. (2004) Transitional traditions: Port Essington bark-paintings and the European discovery of Aboriginal aesthetics. Australian Aboriginal Studies, 2, 77
[7] Dean, C. (1996) The Australian aboriginal "dreamtime”. Gamahucher Press, West Geelong.

[8] Devanesen, D. (1985) Traditional aboriginal medicine and the bicultural approach to health care in Australia's northern territory. In: Larkins, K.P., McDonald, D. and Watson, C., Eds., Alcohol and Drug Use in a Changing Society, Alcohol and Drug Foundation, Canberra.

[9] Soong, F.S. (1983) Role of the margidjbu (traditional healer) in Western Arnhem Land. Medical Journal of Australia, 1, 474-477.

[10] Saggers, S. and Gray, D. (1991) Aboriginal health and society: The traditional and contemporary Aboriginal struggle for better health. Allen and Unwin, Sydney.

[11] Shahid, S., et al. (2010) If you don't believe it, it won't help you: Use of bush medicine in treating cancer among Aboriginal people in Western Australia. Journal of Ethnobiology and Ethnomedicine, 6, 18. doi:10.1186/1746-4269-6-18

[12] Morgan, D.L., Slade, M.D. and Morgan, C.M.A. (1997) Aboriginal philosophy and its impact on health care outcomes. Australian and New Zealand Journal of Public Health, 21, 599.

[13] Maher, P. (1999) A review of "traditional" aboriginal health beliefs. The Australian Journal of Rural Health, 7, 229-236. doi:10.1111/j.1440-1584.1999.tb00462.x

[14] Ricci, J.V. (1943) The genealogy of gynaecology: History of the development of gynaecology throughout the ages, 2000 BC-1800 AD. The Blakiston Company, Philadelphia.

[15] Smellie, W.A. (1783) Treatise on the theory and practice of midwifery. 